\title{
UAV Thermal Infrared Remote Sensing of an Italian Mud Volcano
}

\author{
Stefania Amici ${ }^{*}$, Matteo Turci $^{2}$, Salvatore Giammanco ${ }^{3}$, Letizia Spampinato ${ }^{3}$, Fabrizio Giulietti ${ }^{2}$ \\ ${ }^{1}$ Istituto Nazionale di Geofisica e Vulcanologia, Sezione di Roma, Rome, Italy \\ ${ }^{2}$ Interdepartmental Center for Industrial Research in Aerospace (CIRI Aeronautica), University of Bologna, Bologna, Italy \\ ${ }^{3}$ Istituto Nazionale di Geofisica e Vulcanologia, Osservatorio Etneo, Catania, Italy \\ Email: "stefania.amici@ingv.it, matteo.turci@unibo.it, salvatore.giammanco@ct.ingv.it, \\ letizia.spampinato@ct.ingv.it, fabrizio.giulietti@unibo.it
}

Received August 22, 2013; revised September 22, 2013; accepted September 29, 2013

Copyright (C) 2013 Stefania Amici et al. This is an open access article distributed under the Creative Commons Attribution License, which permits unrestricted use, distribution, and reproduction in any medium, provided the original work is properly cited.

\begin{abstract}
Extreme environments like active volcanoes exhibit many difficulties in being studied by in situ techniques. For example, during eruptions, summit areas are very hard to be accessed because of logistics problems and/or volcanic hazards. The use of remote sensing techniques in the last 20 years by satellite or airborne platforms has proven their capabilities in mapping and monitoring the evolution of volcanic activity. This approach has become increasingly important, as much interest is actually focused on understanding precursory signals to volcanic eruptions. In this work we verify the use of cutting-edge technology like unmanned flying system thermally equipped for volcanic applications. We present the results of a flight test performed by INGV in collaboration with the University of Bologna (Aerospace Division) by using a multi-rotor aircraft in a hexacopter configuration. The experiment was realized in radio controlled mode to overcome many regulation problems which, especially in Italy, limit the use of this system in autonomous mode. The overall goal was not only qualitative but also quantitative oriented. The system flew above an Italian mud volcano, named Le Salinelle, located on the lower South West flank of Mt. Etna volcano, which was chosen as representative site, providing not only a discrimination between hot and cold areas, but also the corresponding temperature values. The in-flight measurements have been cross-validated with contemporaneous in-situ acquisition of thermal data and from independent measurements of mud/water temperature.
\end{abstract}

Keywords: RPAS; Mud Volcano; Thermal Map

\section{Introduction}

Volcanic activities are globally important phenomena affecting both environment and human life. Satellite and airborne remote sensing methodologies have proven to be extremely valuable for examining and evaluating the effects of eruptions over large scale. High temporal resolution systems like MODIS (Moderate Resolution Imaging Spectroradiometer) have been used for mapping the evolution in time of the volcanic plume [1-3]. High spatial resolution systems such as ASTER (Advanced Spaceborne Thermal Emission and Reflection Radiometer) have been extensively used for global scale mapping of volcanoes [4]. During eruptive crisis, on demand, airborne acquisition has provided details on the phenomena allowing the description of the morphology and evolution of lava flow fields $[5,6]$ and thermal anomalies charac-

${ }^{*}$ Corresponding author. terisation [7].

In studies of precursory signals, major indicators of upcoming eruptions are: volcanic tremor [8,9], ground deformation [10], thermal anomalies and gas emissions [11]. Seismic tremor and volcanic gas emissions, for example, are related to upcoming eruptive activity but the mechanisms are not yet completely understood and more data as well as new parameters are needed. Surface temperature anomalies have been remotely investigated, but their use has been limited so far by the poor spatialtemporal resolution of satellite systems or by the expensive costs of dedicated airborne measurements.

Furthermore, these volcanic phenomena rarely maintain a stable level of activity in time and this is the reason why reliable forecasts should be made by well-organized volcano observatories which operate at a local scale. Italy has many active volcanoes that are continuously monitored by the networks of instruments held by the Istituto 
Nazionale di Geofisica e Vulcanologia (INGV), which operates at both ground and airborne scale.

INGV has been using hand-held thermal cameras since 2001 during both ground-based and helicopter-borne surveys for the surveillance and monitoring of Mt. Etna, Stromboli, Vulcano, Campi Flegrei and Vesuvius activity [3,12-17]. Indeed air-borne surveys provide information crucial to get an overall view of the eruptive scenarios, especially in the case of wide active areas such as lava flow fields, crater fumaroles and hydrothermal zones [18]. These surveys provide information to be used for thermal imaging-derived parameters such as heat budgets and effusion rates $[13,17,19]$. However, one of the main drawbacks in the use of helicopters is their cost and the risk for operators and pilots, especially during volcanic paroxysmal phases.

In order to find a compromise between the advantages and disadvantages of air surveys, in 2004 INGV started to investigate the possibility to use remotely, Piloted Air System (RPAS) for volcanic environment applications. The first test was carried out by a joint collaboration between INGV and Università di Bologna seven years ago at Stromboli volcano [20,21]. From that period of time, the activity has evolved with the aim of equipping systems with sophisticated instrumentation which could support the scientists work. Great efforts have been made in order to study how to improve technical systems and instrumentations for risk management including volcanology. Telemetry and, in real time, acquisition system have been developed and tested at laboratory-field scale [22]. In this paper we describe a field experiment performed in June 2012 by flying a thermal camera-equiped hexacopter over the Salinelle mud volcano (Sicily, Italy). Firstly, we describe the main platform and the characteristics of the sensor used for the experiment; secondly we describe the geological setting of the investigated area. Finally, we discuss the results, including the cross comparison between in-flight and in-situ independent thermal mapping. The relevant result is that we not only realized qualitative hot-cold map of the mud volcano, but also associated the temperature values.

\section{Methods}

\subsection{The Multirotor System}

The unmanned system used for our purposes is a rotorcraft with six rotors (hexacopter). This kind of aircraft uses fixed-pitch blade and brushless motor rigidly fixed to the structure. Since the speed of each rotor can be independently regulated, the control of model, in terms of attitude, position ad movement, is obtained by modifying the trust and torque produced by each rotors; this effect is obtained simply by modifying the relative speed of each rotor.
Since this kind of vehicles are generally unstable, a Flight Controller Board (FCB) which include GPS receiver, air pressure sensor, Inertial Measurement Unit, is installed. The FCB allows to use the radio-controlled system.

The multicopter in hexacopter configuration, used in our work, is the Easy fly A2500 (www.salengeneering.it); this model has been improved in rigidity and weight by using carbon fiber parts instead of aluminum. It has a diameter of $100 \mathrm{~cm}$ and a height, from ground to the center plate, of $30 \mathrm{~cm}$. It is powered by two battery packs $(5000+5000 \mathrm{mAh})$ allowing an autonomous flight of about $15 \mathrm{~min}$ - $20 \mathrm{~min}$ according to the batteries and payload (Figure 1). In our configuration, the payload weight was $1.7 \mathrm{Kg}$ and the estimated maximum ceiling of $200 \mathrm{~m}$ (70 $\mathrm{m}$ by ENAC Italian regulation). Due to limitation in national regulation in matter of RPAS, the system flew in line of sight and by radio control. For the experiment, the hexacopter was equipped with a thermal EYE 3600 AS (TE 3600 AS) designed for Original Equipment Manufacturers (OEMs). The TE 3600 AS is microbolometer technology based consisting of $30 \mu \mathrm{m}$ pitch detectors, which make possible a lightweight of $67 \mathrm{~g}$. The spectral response is in the range $7-14 \mu \mathrm{m}$ with a thermal sensitivity less than $50 \mathrm{mK}$ and a saturation temperature of $600^{\circ} \mathrm{C}$. The camera has a frame rate of 25 hertz real time and generates a PAL video output. The camera is characterized by an automatic contrast that is decreased and increased according the scene. For each thermogram acquired by the camera a calibrated temperature value is provided in correspondence of the central spot while a color scale bar on the right side of the image shows the minimum and maximum temperature range expressed in decimal Celsius degrees. To integrate the camera with the system an acquisition system has been developed based on the philosophy to use commercial components. The result is a cubic embedded solution $(12 \mathrm{~cm} \times 11 \mathrm{~cm}$ $\times 8 \mathrm{~cm}$, and weight of $600 \mathrm{gr}$ ) composed of four PC-104 compliant stackable modules: Power supply, Frame grabber, PC and Wi-Fi module [22]. In order to fix both

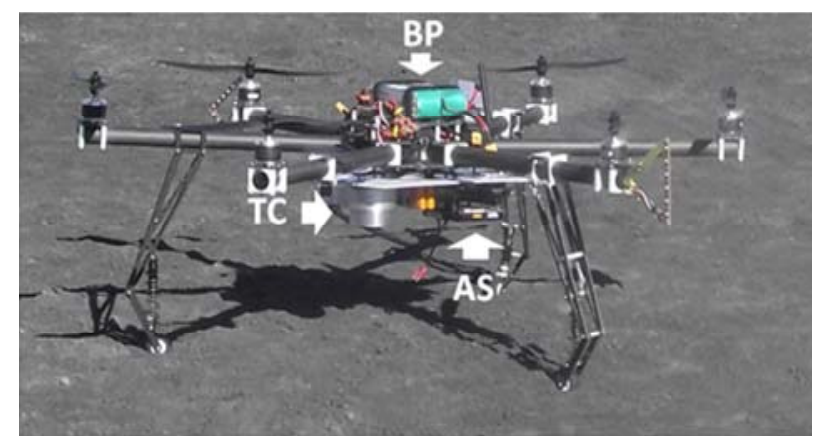

Figure 1. Hexacopter UAV system: the locations of battery pack (BP), thermal camera (TC) and acquisition system (AS) are shown. 
camera and acquisition system on the hexacopter, MDV designed and realized a specific set-up. Aluminum was preferred for its low weight. A standard female USB connector allows the GUI communication and A DB9 connector reports all camera pins, including analogue video output was properly configured. The final flight configuration including payload and acquisition system is shown in Figure 1.

\subsection{Geological Setting of the Salinelle Mud Volcano}

The Salinelle mud volcanoes occur in three sites located on the lower SW flank of Mt. Etna volcano (Italy) Figure 2. The geology of the area includes: 1) volcanic products erupted from Mt. Etna (Mongibello cycle, dated $35 \mathrm{ka}$ to Present, [23] that outcrop in the northern and north- eastern parts of the area; 2) terraced alluvial deposits (mostly conglomerates and clays) dated to 125 to $40 \mathrm{ka}$ [23]; 3) small outcrops of alkali lavas belonging to the Timpe phase [24] that are present in the central and north-western parts of the area, and are best represented by the volcanic neck of Paternò [25], whose age was calculated at $168 \mathrm{ka}$ by [26] or at $210 \mathrm{ka}$ by Condomines [27]; 4) sub-alkalic lavas dated to 580 to $250 \mathrm{ka} \mathrm{[23];5)}$ Early-Middle Pleistocene foredeep deposits (1200 - 600 ka) mostly made of marly clays [23] that fill the Catania basin and outcrop in the eastern part of the area; 6) units of the Apenninic-Maghrebian collision belt, mostly composed of quartz-arenites and clays [28,23]. For the purposes of this study, the best site for the test was that of the Salinelle of Paternò Stadium, located at the NW boundary of the city of Paternò very close to the local football stadium. In this site fluid emissions occur on alkali lavas close to the Paternò volcanic neck (Figure 2(c)). The fluids escaping from these manifestations are composed of a gas phase and hypersaline waters that often pond in pools that range in size from centimeters to

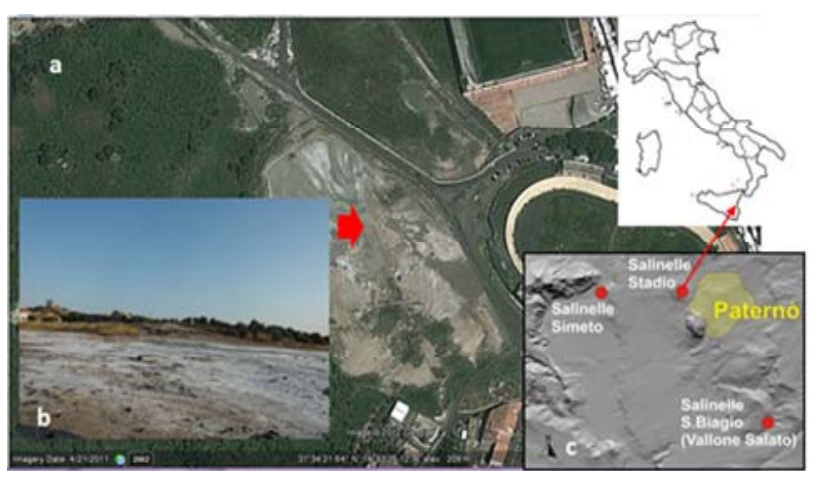

Figure 2. (a) Visible image as acquired by GeoEYE (Google

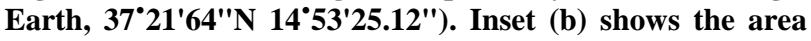
selected for take-off and landing of the hexacopter UAV system; inset (c) shows the location of the three mud volcanoes named "Le Salinelle". meters in diameter. The mud and water mixtures are highly variable, and in some cases mud is the only fluid erupted with gas, and it builds cones up to a few meters high and with a base diameter up to about ten meters. Emitted waters have rather uniform and constant chemical compositions and physical-chemical characteristics; their $\mathrm{pH}$ is about 6 , the electrical conductivity of about $88 \mathrm{mS} / \mathrm{cm}$, the chemical abundance of major species in solution (on equivalent basis) is $\mathrm{Na}>>\mathrm{Ca}>\mathrm{Mg}>\mathrm{K}$ and $\mathrm{Cl}^{-}>\mathrm{HCO}_{3}^{-}>\mathrm{SO}_{4}=$ [29-31]. During the summer intense evaporation produces large salt crusts around the emission vents, hence the name of such manifestations (from the Italian word "sale", which means salt). Most of the pools and mud vents are ephemeral and show strong temporal variations in the gas flow. Water outlet temperatures are normally between $10^{\circ} \mathrm{C}$ and $20^{\circ} \mathrm{C}$, but occasionally increase to $40^{\circ} \mathrm{C}-50^{\circ} \mathrm{C}[31,32]$. Such anomalous temperature values are always accompanied by increases in the gas efflux.

Many paroxysms occurred in the degassing activity of the Salinelle in the past. $[31,32]$ reports of strong eruptive activities in early 1866 and late 1878 , with fountains of muddy water up to $3 \mathrm{~m}$ high and water temperature up to $46^{\circ} \mathrm{C}$, that the author relates to local seismic events that occurred some days/weeks prior to the gas eruptions. During the past 15 years similar increases in degassing activity have also been recorded at the Salinelle [S. Giammanco, unpublished data]. These events normally lasted from two to four months. The main component of the gas escaping from the studied sites is $\mathrm{CO}_{2}$. In all of the sites, air components are very low or are absent. Methane is normally the second most abundant gas species, although with highly variable amounts among the sites. Other minor species emitted include $\mathrm{N}_{2}, \mathrm{He}, \mathrm{H}_{2}$, $\mathrm{CO}, \mathrm{H}_{2} \mathrm{~S}, \mathrm{Rn}$ and other light hydrocarbons [29,30].

Normally, gases from the Salinelle are sampled by using inverted funnels placed on the ground over the smallest vents or on the water/mud surface right over gas bubbling areas in the case of larger vents, where accessible. Funnels are connected to gas flasks for gas collection. Field measurements of water/mud temperature are normally carried out using thermocouples when vents are directly accessible or using laser devices from a distance. Since 2006, water/mud temperature measurements were carried out only using a non-contact laser-guided IR temperature meter (Fluke Corporation, WA, US, mod. Fluke 68), with accuracy of $\pm 1 \%$ for targets above $23^{\circ} \mathrm{C}$ and of $\pm 2^{\circ} \mathrm{C}$ for targets between $-18^{\circ} \mathrm{C}$ and $23^{\circ} \mathrm{C}$. However, due to the large variability both in the position of gas and water vents and in the gas flux, the use of devices able to easily and quickly monitor the whole degassing area is fundamental.

\subsection{Experimental Setup and Results}

The experimentation was carried out on 26 June 1012 . 
The hexacopter was pre-assembled while payload and system were configured in situ. The weather conditions were favorable though the day: air was extremely hot even in the afternoon (up to $32.2^{\circ} \mathrm{C}$, as reported by meteo Sicilia, http://meteosicilia.it). The flights were planned during the early evening in order to reduce the effects of heat and reflection from the ground [33]. The autonomy of the system was about $15 \mathrm{~min}$, so we could carry out only two flights to cover two different areas of the Salinelle. Although the site has a good accessibility, it is located in a urban area, hence both take-off and landing had to be performed at the edge of the mud volcano area, that is a zone characterized by unstable muddy surface (Figure 3). In order to verify the suitability of the method in extreme environment conditions, we tested the stability of the acquisition and of the transmission systems. Then we investigated the possibility to obtain both qualitative (mapping of the active degassing areas) and quantitative (temperature distribution) thermal information. In order to obtain a quantitative mapping of the Salinelle volcano, a Forward Looking InfraRed (FLIR) thermal camera was used. The FLIR camera was a A310 model consisting of a $320 \times 240$ microbolometer detector array operating in the $8-14 \mu \mathrm{m}$ waveband, with dynamic range of $0^{\circ} \mathrm{C}$ to $350^{\circ} \mathrm{C}$ and accuracy of $\pm 2 \%$ of reading (see http://www.flir.com for more details).

Six thermogram from the video recorded by thermal EYE 3600 in correspondence of six areas in the FLIR image were processed [34] to choose the area for comparison Figure 4.

Similarly to the ground-based temperature measurements of one of the cold pools yielding mean values of about $34.7^{\circ} \mathrm{C}$ (Figure 4(b)), apparent temperatures of the same pool measured in-flight gave values of about $34^{\circ} \mathrm{C}$ as well (Figure 5(c)). We observed that the good agreement was reached despite the different viewing geometry of the two cameras (i.e. horizontal in the case of the FLIR camera, vertical in the case of the drone-borne camera).

For emissivity we used a value of 0.95 derived by an emissivity spectrum measured by $\mu$ FTIR one day after (Figure 5) and in agreement with same values for soil saturated with water [35].

The second flight was performed in the area which is usually mapped by the field laser system. This site is characterized by a quite large area affected by water and $\mathrm{CO}_{2}$ emissions. We meant to compare the temperature measured by the in-flight system with the measurement realized in an independent method. Figure 6 shows the area investigated during the second hexacopter flight and the thermal frame acquired in correspondence of the site regularly mapped. The temperature detected at the center of the TC3600 image is $22^{\circ} \mathrm{C}$.

Figure 7 shows the time series of the Salinelle highest

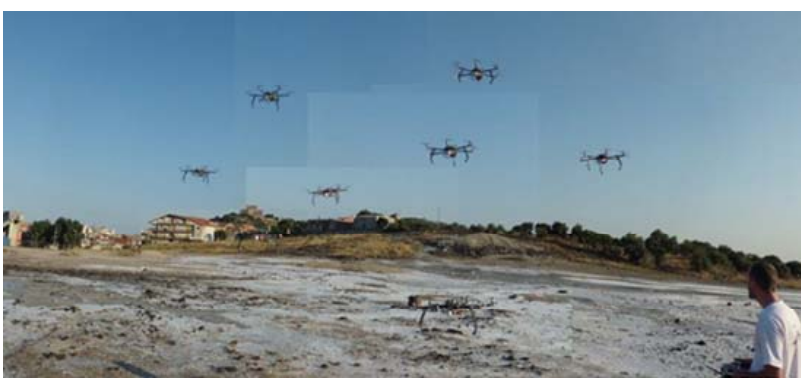

Figure 3. The frame composite visible image shows the reconstructed pattern of the first hexacopter flight.
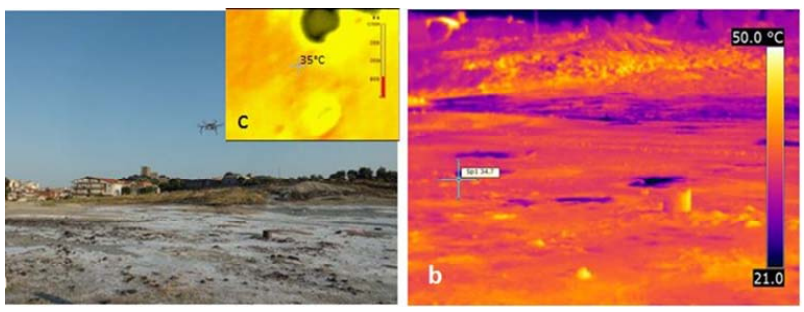

Figure 4. (a) Visible image of the area selected for the first flight; (b) thermal image acquired by FLIR camera, the spot is located in correspondence of the same area as seen by the TC 3600 (c).

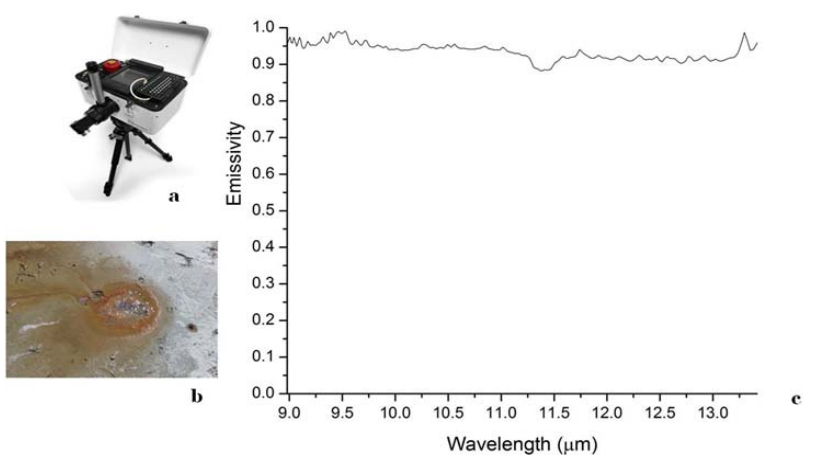

Figure 5. (a) $\mu$ FTIR instrument used to measure emissivity spectrum; (b) Visible image of one of cold pool $(20 \mathrm{~cm}$ diameter) that was possible to access; (c) Emissivity measured spectrum.

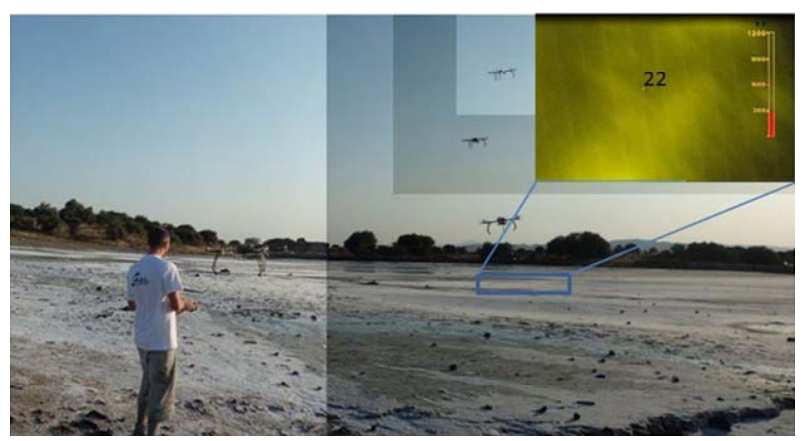

Figure 6. The frame composite visible image shows the reconstructed pattern of the second hexacopter flight. Inset shows the frame from the drone-borne thermal camera taken on the same site as field temperature measurements and the temperature measured in the centre of the image. 


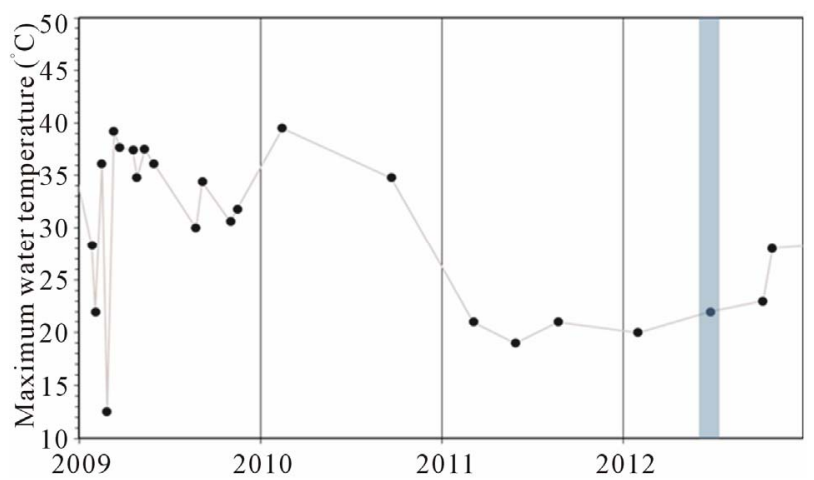

Figure 7. Temporal pattern of the highest water temperature measured in the mud pools of the Salinelle mud volcanoes during the period 2009-2012 using field instruments. The vertical blue stripe highlights the temperature measured on June 27, 2012. A thermogram corresponding to the same site as this field measurement has been extracted and shown in figure 6.

temperature acquired during direct field surveys carried out from 2009 to 2012 The vertical blue stripe outlines the measurement acquired on June 27, 2012, during the period of time when the hexacopter flights were performed. The measured temperature was $22^{\circ} \mathrm{C} \pm 0.4^{\circ} \mathrm{C}$, therefore comparable to the temperature value extracted from the frame taken by the drone-borne thermal camera (see Figure 6).

\section{Conclusions}

Thermal mapping of volcanoes at super-spatial resolution scale is important for investigating thermal anomalies which can be related to upcoming volcanic eruptions. RPAS cutting edge technology and sophisticated lightweight thermal camera have been used in an experiment conducted on a very active Italian mud volcano: the Salinelle of Paternò. The mud volcano is located on the southwest boundary of Mt. Etna volcano (Italy).

The site was chosen for the flight test for different reasons: it is easy access and it has peculiar geological features which in certain case are related to Etna activity and make it a very interesting site. Furthermore, it is an example of difficult area to be monitored by in situ measurements due to the muddy surface.

A hexacopter thermally equipped and connected with an embedded acquisition system specifically designed for the scope was flying on the mud volcano. The experiment was performed in June 2012 and two areas were mapped: an area, corresponding to the area usually mapped by in situ measurements, and an area never mapped before. This second area was used to cross validate images acquired by the hexacopter with images acquired by a ground FLIR camera. The thermal camera flew above the usually measured area and the acquired temperature was compared to the temperature obtained by laser measure- ment time series (2009-2012) showing a good correspondence. The experiment was a success from both technical and scientific points of view. Technically speaking, the flying system worked properly; a thermal video was recorded and transmitted in real time during the whole flight time, despite take-off and landing occurred under extreme environmental conditions. Scientifically speaking, we found a good agreement between temperatures acquired in-flight and those acquired in-situ with different field instruments. Thermal imaging on board of unmanned system therefore proves to be a promising technique for distinguish thermal gradient and temperature values in volcanic application. In particular we would like to use the hexacopter in some areas on the top of Mount Etna, which exhibit thermal anomalies and, actually are very hard to be measured with super resolution.

\section{Acknowledgements}

We would like to thank Dr. A. La Spina, and T. Caltabiano of Catania INGV branch for logistic and support in field measurements. A special thanks to Dr M. F. Buongiorno head of CNT Unit of Roma INGV for supporting this research. The authors wish to thank Mario Gattelli and Massimiliano Pompignoli for providing the experimental UAV airframe.

\section{REFERENCES}

[1] R. Wright, L. L. Flynn, H. Garbeil, A. Harris and E. Pilger, "Automated Volcanic Eruption Detection Using MODIS," Remote Sensing of Environment, Vol. 82, No. 1, 2002, pp. 135-155. http://dx.doi.org/10.1016/S0034-4257(02)00030-5

[2] S. Corradini, C. Spinetti, E. Carboni, C. Tirelli, M. F. Buongiorno, et al., "Mt. Etna Tropospheric Ash Retrieval and Sensitivity Analysis Using Moderate Resolution Imaging Spectroradiometer Measurements," Journal of Applied Remote Sensing, Vol. 2, No. 1, 2008, Article ID: 023550. http://dx.doi.org/10.1117/1.3046674

[3] S. Corradini, L. Merucci, A. J. Prata and A. Piscini, "Volcanic Ash and $\mathrm{SO}_{2}$ in the 2008 Kasatochi Eruption: Retrievals Comparison from Different IR Satellite Sensors," Journal of Geophysical Research Atmospheres, Vol. 115, No. D2, 2010, pp. 2156-2202. http://dx.doi.org/10.1029/2009JD013634

[4] D. Pieri and M. Abrams, "ASTER Watches the World's Volcanoes: A New Paradigm for Volcanological Observations from Orbit," Journal of Volcanology and Geothermal Research, Vol. 135, No. 1-2, 2004, pp. 13-28. http://dx.doi.org/10.1016/j.jvolgeores.2003.12.018

[5] V. Lombardo, M. F. Buongiorno, D. Pieri and L. Merucci, "Differences in Landsat TM Derived Lava Flow Thermal Structures during Summit and Flank Eruption at Mount Etna," Journal of Volcanology and Geothermal Research, Vol. 134, No. 1-2, 2004, pp. 15-34.

http://dx.doi.org/10.1016/j.jvolgeores.2003.12.006 
[6] C. Spinetti, V. Carrère, M. F. Buongiorno, A. J. Sutton and T. Elia, "Carbon Dioxide of Pu'u'O'o Volcanic Plume at Kilauea Retrieved by AVIRIS Hyperspectral Data," Remote Sensing of Environment, Vol. 112, No. 6, 2008, pp. 3192-3199.

http://dx.doi.org/10.1016/j.rse.2008.03.010

[7] D. Pieri and M. Abrams, "ASTER Observations of Thermal Anomalies Preceding the April 2003 Eruption of Chikurachki Volcano, Kurile Islands, Russia," Remote Sensing of Environment, Vol. 99, No. 1-2, 2005, pp. 84-94. http://dx.doi.org/10.1016/j.rse.2005.06.012

[8] R. Schick, "Volcanic Tremor-Source Mechanisms and Correlation with Eruptive Activity," Natural Hazards, Vol. 1, No. 2, 1988, pp. 125-144. http://dx.doi.org/10.1007/BF00126610

[9] M. Cosentino, G. Lombardo and E. Privitera, "A Model for Internal Dynamical Processes on Mt Etna," Geophysical Journal International, Vol. 97, No. 3, 1989, pp. 367-379. http://dx.doi.org/10.1111/j.1365-246X.1989.tb00508.x

[10] W. J. Glyn and R. Hazel, "Detecting Volcanic Eruption Precursors: A New Method Using Gravity and Deformation Measurements," Journal of Volcanology and Geothermal Research, Vol. 113, No. 3-4, 2002, pp. 379-389. http://dx.doi.org/10.1016/S0377-0273(01)00272-4

[11] A. Aiuppa, R. Moretti, C. Federico, G. Giudice, S. Gurrieri, M. Liuzzo, P. Papale, H. Shinohara and M. Valenza, "Forecasting Etna Eruptions by Real-Time Observation of Volcanic Gas Composition," Geology, Vol. 35, No. 12, 2007, pp. 1115-1118.

http://dx.doi.org/10.1130/G24149A.1

[12] V. Lombardo and M. F. Buongiorno, "Temperature Distribution Analysis of July 2001 Mt. Etna Eruption Observed by the Airborne Hyperspectral Sensor MIVIS," Annals of Geophysics, Vol. 46, No. 6, 2003, pp. 12171228.

[13] S. Calvari, L. Spampinato, L. Lodato, A. J. L. Harris, M. R. Patrick, J. Dehn, M. R. Burton and D. Andronico, "Chronology and Complex Volcanic Processes during the 2002-2003 Flank Eruption at Stromboli Volcano (Italy) Reconstructed from Direct Observations and Surveys with a Handheld Thermal Camera," Journal of Geophysical Research: Solid Earth, Vol. 110, No. B2, 2005, Article ID: B02201. http://dx.doi.org/10.1029/2004JB003129

[14] G. Chiodini, G. Vilardo, V. Augusti, D. Granieri, S. Caliro, C. Minopoli and C. Terranova, "Thermal Monitoring of Hydrothermal Activity by Permanent Infrared Automatic Stations: Results Obtained at Solfatara di Pozzuoli, Campi Flegrei (Italy)," Journal of Geophysical Research: Solid Earth, Vol. 112, No. B12, 2007, Article ID: B12206. http://dx.doi.org/10.1029/2007JB005140

[15] C. Spinetti and M. F. Buongiorno, "Volcanic Aerosol Optical Characteristics of Mt. Etna Tropospheric Plume Retrieved by Means of Airborne Multispectral Images," Journal of Atmospheric and Solar-Terrestrial Physics, Vol. 69, No. 9, 2007, pp. 981-994.

[16] L. Spampinato, S. Calvari, C. Oppenheimer and L. Lodato, "Shallow Magma Transport for the 2002-3 Mt. Etna
Eruption Inferred from Thermal Infrared Surveys," Journal of Volcanology and Geothermal Research, Vol. 177, No. 2, 2008, pp. 301-312. http://dx.doi.org/10.1016/j.jvolgeores.2008.05.013

[17] A. J. L. Harris, L. Lodato, J. Dehn and L. Spampinato, "Thermal Characterization of the Vulcano Fumarole Field," Bulletin of Volcanology, Vol. 71, No. 4, 2009, pp. 441-458. http://dx.doi.org/10.1007/s00445-008-0236-8

[18] P. Allard, M. Burton and F. Muré, "Spectroscopic Evidence for a Lava Fountain Driven by Previously Accumulated Magmatic Gas," Nature Letters, Vol. 433, No. 7024, 2005, pp. 407-410.

[19] L. Spampinato, S. Calvari, C. Oppenheimer and E. Boschi, "Volcano Surveillance Using Infrared Cameras," Earth-Science Reviews, Vol. 106, No. 1-2, 2011, pp. 6391. http://dx.doi.org/10.1016/j.earscirev.2011.01.003

[20] S. Amici, G. M. Saggiani, M. F Buongiorno, F. Persiani, A. Ceruti, P. Tortora, E. Troiani, F. Giulietti, G. DiStefano, D. Pieri, G. G. Bentini M. Bianconi, A. Cerutti, A. Nubile, S. Sugliani, S. Chiarini, G. Pennestrì and S. Petrini, "A UAV System for Observing Volcanoes and Natural Hazards," Fall Meeting of American Geophysical Union, San Francisco, 11-14 December 2007.

[21] G. M. Saggiani, F. Persiani, A. Ceruti, P. Tortora, E. Troiani, F. Giulietti, S. Amici, M. F. Buongiorno, G. G. Bentini, M. Bianconi, A. Cerutti, A. Nubile, S. Sugliani, M. Chiarini, G. Pennestrì, S. Petrini and R. Guzzi, "UAV System Development for the Monitoring and Study Volcanic and Natural Hazard Events," Proceeding of RSPSOC, New Castle, 11-14 September 2007.

[22] M. Turci, S. Amici, M. F. Buongiorno, F. Giulietti and N. A. Melega, "A Thermal EYE on Unmanned Aircraft System," Technical Report INGV, 2011, ISSN-2039-7941, n. 210.

[23] S. Catalano, S. Torrisi and C. Ferlito, "The Relationship between Late Quaternary Deformation and Volcanism of Mt. Etna (eastern Sicily): New Evidence from the Sedimentary Substratum in the Catania Region," Journal of Volcanology and Geothermal Research, Vol. 132, No. 4, 2004, pp. 311-334.

http://dx.doi.org/10.1016/S0377-0273(03)00433-5

[24] S. Branca, M. Coltelli and G. Groppelli, "Geological Evolution of Etna Volcano," In: A. Bonaccorso, S. Calvari, M. Coltelli, C. Del Negro and S. Falsaperla, Eds., Mt. Etna: Volcano Laboratory, American Geophysical Union, Washington DC, 2004, pp. 49-63.

[25] D. K. Chester, A. M. Duncan, J. E. Guest and C. R. J. Kilburn, "Mount Etna: The Anatomy of a Volcano," Chapman and Hall, London, 1985.

[26] P. Y. Gillot, G. Kieffer and R. Romano, "The Evolution of Mount Etna in the Light of Potassium-Argon Dating," Acta Vulcanologica, Vol. 5, 1994, pp. 81-87.

[27] M. Condomines, J. Tanguy and V. Michaud, "Magma Dynamics at Mt. Etna-Constraints from U-Th- Ra-Pb Radioactive Disequilibria and $\mathrm{Sr}$ Isotopes in Historical Lavas," Earth and Planetary Science Letters, Vol. 132, No. 1-4, 1995, pp. 25-41. http://dx.doi.org/10.1016/0012-821X(95)00052-E

[28] F. Lentini, "The Geology of Mt. Etna Bas," Mem. Soc. 
Geol. It., Vol. 23, 1982, pp. 7G-25G.

[29] G. Chiodini, W. D'Alessandro and F. Parello, "1982. Geochemistry of Gases and Waters Discharged by the Mud Volcanoes at Paternò, Mt. Etna (Italy)," Bulletin of Volcanology, Vol. 58, No. 1, 1996, pp. 51-58. http://dx.doi.org/10.1007/s004450050125

[30] W. D'Alessandro, F. Parello and M. Valenza, "Gas Manifestations of Mount Etna Area: Historical Notices and New Geochemical Data (1990-1993)," Acta Vulcanologia, Vol. 8, No. 1, 1996, pp. 23-29.

[31] O. Silvestri, "Le Salse e la Eruzione di Fango di Paternò (Sicilia)," Osservazioni e Ricerche. Stabilimento Tipografico, C. Galatola, Catania, 1866, p. 30.

[32] O. Silvestri, "Importante Eruzione di Fango Comparsa a Paternò Nelle Adiacenze Dell'Etna ai Primi di Dicembre
1878," Bollettino di Vulcanologia Italiana, Vol. 5, 1878 , pp. 131-132.

[33] L. Spampinato, C. Oppenheimer, A. Cannata, P. Montalto, G. G. Salerno and S. Calvari, "On the Time-Scale of Thermal Cycles Associated with Open-Vent Degassing," Bulletin of Volcanology, Vol. 74, No. 6, 2012, pp. 12811292. http://dx.doi.org/10.1007/s00445-012-0592-2

[34] S. Amici, M. Turci. F. Giulietti, S. Giammanco, M. F. Buongiorno, A. La Spina and L. Spampinato, "Volcanic Environments Monitoring by Drones Mud Volcano Case Study," International Archives of the Photogrammetry, Remote Sensing and Spatial Information Sciences, Vol. XL-1/W2, UAV-G, 4-6-2013, Rostock, 2013, p. 1.

[35] http://www.infrared-thermography.com/material-1.htm 